\title{
La culture au service de la diplomatie ? Les politiques culturelles extérieures de la RFA et de la France au Brésil (1961-73)
}

\section{Élise Lanoe}

\section{OpenEdition}

\section{Journals}

Édition électronique

URL : http://journals.openedition.org/ifha/7416

DOI : 10.4000/ifha.7416

ISSN : 2198-8943

\section{Éditeur}

IFRA - Institut franco-allemand (sciences historiques et sociales)

\section{Édition imprimée}

Date de publication : 1 décembre 2013

ISSN : 2190-0078

\section{Référence électronique}

Élise Lanoe, "La culture au service de la diplomatie? Les politiques culturelles extérieures de la RFA et de la France au Brésil (1961-73) », Revue de I'IFHA [En ligne], 5 | 2013, mis en ligne le 17 février 2014, consulté le 01 mai 2019. URL : http://journals.openedition.org/ifha/7416 ; DOI : 10.4000/ifha.7416

Ce document a été généré automatiquement le 1 mai 2019.

(CIFHA 


\title{
La culture au service de la diplomatie ? Les politiques culturelles extérieures de la RFA et de la France au Brésil (1961-73)
}

\author{
Élise Lanoe
}

\section{NOTE DE L'ÉDITEUR}

Thèse de doctorat sous la direction de Jérôme Vaillant, université de Lille 3, soutenue le 21 mai 2012 à Lille.

1 Cette étude met en regard les politiques culturelles extérieures de la RFA et de la France entre 1961 et 1973 en direction du Brésil. L'articulation entre la culture et la diplomatie qui préside aux pratiques de la politique culturelle extérieure est au cœur des interrogations. On insiste tout particulièrement sur les convergences et différences d'approches franco-allemandes dans ce champ des politiques culturelles extérieures.

2 Le travail porte tout d'abord sur la manière dont les échanges culturels ont été mis au service des grands enjeux des relations internationales, particulièrement durant la période 1961-66. La Guerre froide et l'antagonisme entre les deux Allemagnes en constituent l'arrière-plan, tout autant que, du côté français, les mouvements de décolonisation et la guerre d'Algérie. À cet égard, on note une analogie entre les cas allemand et français, la rivalité interallemande conduisant comme la rivalité francoalgérienne à l'instauration de politiques culturelles comparables dans leur combativité. Les diplomaties culturelles se manifestent en effet par l'emploi de moyens culturels spécifiques (documents audiovisuels, diffusion de brochures, expositions) au service de la politique d'information et de propagande. À cet égard, le Brésil joue moins le rôle de pays cible des politiques culturelles extérieures que le rôle de réceptacle de luttes qui se déroulent entre pays tiers. 
3 L'auteur examine ensuite la manière dont les politiques culturelles extérieures de la RFA et de la France s'articulent de plus en plus étroitement avec les relations bilatérales germano- et franco-brésiliennes. À la faveur des Trente Glorieuses, l'époque est en effet marquée par un resserrement des relations commerciales avec le Brésil, alors en pleine croissance économique malgré les tensions politiques liées à l'instauration du régime autoritariste en 1964. Dans ce contexte, la culture se voit attribuer un rôle de soutien à l'économie : soutien plutôt accessoire côté allemand, soutien conçu comme essentiel côté français. De fait, tandis que les relations germano-brésiliennes se resserrent dès 1964 autour de la lutte commune contre le communisme et engendrent un partenariat économique sans précédent dans les années 1964-71, les relations franco-brésiliennes subissent le contrecoup de la perte de prestige lié à la débâcle de 1940 et à la décolonisation des années 1950-60. La culture française apparaît aux acteurs diplomatiques français comme une planche de salut pour relancer les relations économiques et politiques, alors que du côté allemand la culture n'apporte qu'un plus ornemental à des liens commerciaux déjà intenses.

Enfin, à la fin des années 1960, l'action des instituts culturels est soumise à un changement de paradigme : l'idée de réciprocité des échanges s'impose dans un contexte socioculturel européen marqué par le tiers-mondisme et les révoltes étudiantes. Dans le Brésil de la dictature militaire, l'instrumentalisation de la culture par la diplomatie est remise en cause, par le public brésilien comme par les directeurs d'Instituts Goethe désireux de tirer les enseignements du passé nazi. Du côté français en revanche, malgré les révoltes étudiantes qui font parler d'elles à Paris et qui inspirent en bonne partie les protestations politiques des étudiants brésiliens, la diplomatie culturelle reste peu marquée par ce changement de paradigme observé côté allemand. De fait, le renouvellement des arts de l'époque, à travers l'émergence d'un cinéma politisé, d'un nouveau réalisme pictural et d'un théâtre engagé n'ont que peu d'effet sur les pratiques des Alliances françaises et des services culturels des ambassades. Ainsi, alors que les Instituts Goethe tentent d'instaurer une action culturelle fondée sur le dialogue avec le public, la réciprocité des échanges et la subversion des limites posées par le régime militaire, les Alliances françaises et services culturels restent majoritairement dans une ligne de non-immixtion dans les affaires intérieures du pays et continuent de pratiquer l'export culturel unilatéral. Dans la dernière partie de la thèse l'auteur tente de trouver des éléments d'explication de ce décalage franco-allemand. Pour ce faire, elle s'intéresse de près à l'historique des institutions de la politique culturelle extérieure, à la trajectoire des acteurs en question et à la question plus générale du rapport à l'histoire qui se manifeste dans les diplomaties culturelles. 